


Sor JUANA INÉS DE LA CRUZ Y EL TEATRO NOVOHISPANO 


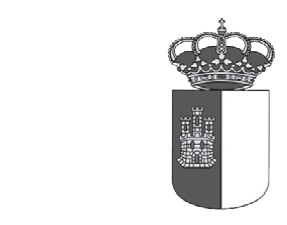

\section{CoRTes DE \\ Castilla-La Mancha}
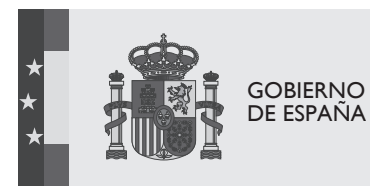

MINISTERIO

DE ECONOMÍA

Y COMPETITIVIDAD

FFI2017-87523-P 


\title{
Sor Juana Inés de la Cruz y el teatro novohispano
}

\author{
XLII Jornadas de teatro clásico
}

Almagro, 9, 10 y 11 de julio de 2019

Edición cuidada por

Rafael González Cañal

y

(ู) $\frac{\text { Ediciones de la Universidad }}{\text { de Castilla-La Mancha }}$

2021 


\section{JORNADAS DE TEATRO CLÁSICO DE ALMAGRO}

(42․ 2019. Almagro)

Sor Juana Inés de la Cruz y el teatro novohispano: XLII jornadas de teatro clásico, Almagro, 9, 10 y 11 de julio de 2019 / edición cuidada por Rafael González Cañal y Almudena García González.- [Cuenca] : Ediciones de la Universidad de Castilla-La Mancha, 2021.

224 p.; $24 \mathrm{~cm}$.- (Corral de comedias ; 45)

ISBN: 978-84-9044-457-3

1. Sor Juana Inés de la Cruz. 2. Teatro español - S. XVII - Historia y crítica I. González Cañal, Rafael, ed. lit. II. García González, Almudena, ed. lit. III. Universidad de Castilla-La Mancha, ed. V. Título VI. Serie

821.134.2-2.09 “16”(063)

(C) de los textos: sus autores.

(C) de la edición: Universidad de Castilla-La Mancha.

Edita: Servicio de Publicaciones de la Universidad de Castilla-La Mancha.

Director: César Sánchez Ortiz.

Colección CORRAL DE COMEDIAS, núm. 45.

Director: Felipe B. Pedraza Jiménez.

$1^{a}$ ed. Tirada: 200 ejemplares.

Diseño de la cubierta: C.I.D.I (Universidad de Castilla-La Mancha)

Composición y maquetación: Añil desarrollo gráfico -anil.es-

Impresión: Masquelibros.

Impreso en España (U.E.) - Printed in Spain (U.E.)

ISBN: 978-84-9044-457-3 (edición impresa)

D.L. CU 55-2021

ISBN: 978-84-9044-458-0 (edición electrónica)

ISSN: $1699-8650$

Doi: http://doi.org/10.18239/cor_45.2021.00

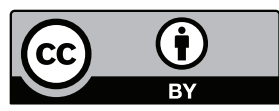

Esta obra se encuentra bajo una licencia internacional Creative Commons CC BY 4.0.

Cualquier forma de reproducción, distribución, comunicación pública o transformación de esta obra no incluida en la licencia Creative Commons CC BY 4.0 solo puede ser realizada con la autorización expresa de los titulares, salvo excepción prevista por la ley. Puede $\mathrm{Vd}$. acceder al texto completo de la licencia en este enlace: https://creativecommons.org/licenses/by/4.0/deed.es 


\section{Palabras preliminares}

Por primera vez me toca a mí redactar estas palabras preliminares que abren el volumen de las actas de las Jornadas de teatro clásico de Almagro. En las veintisiete ocasiones anteriores en que la Universidad de Castilla-La Mancha ha organizado las Jornadas de teatro clásico de Almagro, ha sido mi compañero Felipe B. Pedraza el encargado de esta presentación, pero en 2019 decidió retirarse de las Jornadas con la misión cumplida después de un trabajo de muchos años. Él ha consolidado y mantenido esta actividad contra viento y marea. Hoy podemos decir que nuestras Jornadas almagreńas se han convertido en todo un referente del diálogo y el entendimiento entre los estudiosos e investigadores y la gente del teatro que tanto se ha venido demandando. No podemos más que agradecerle su trabajo y entusiasmo a lo largo de tantos ańos.

Para celebrar las XLII Jornadas contamos con la ayuda de diferentes instituciones a las que queríamos agradecer su apoyo y su confianza: el Instituto Almagro de teatro clásico, las Cortes de Castilla La Mancha y la Facultad de Letras de nuestra universidad.

Además, disfrutamos de la presencia de colegas y amigos que vinieron a apoyar nuestras Jornadas de una manera desinteresada y entusiasta: Matías Barchino, decano de la Facultad de Letras, que colaboró generosamente en esta edición; Antonio Serrano, director de las Jornadas de Teatro del Siglo de Oro de Almería durante muchos años, que se encargó de moderar el coloquio de los directores escénicos; Luciano García Lorenzo, que también dirigió algunas ediciones de estas Jornadas en los primeros tiempos y que, después fue director del Festival de Almagro durante ocho años; Francisco Domínguez Matito que trajo a Almagro un nutrido grupo de becarios de la Universidad de La Rioja; y Mar Zubieta, fiel amiga de las Jornadas, que presentó las publicaciones de la Compañía Nacional de Teatro Clásico. A todos ellos, mi agradecimiento. 
Y he de dedicar también unas palabras de gratitud a los asistentes, a todos los que han querido dedicar su tiempo a reflexionar sobre esa figura apasionante que es Sor Juana Inés de la Cruz. A ella le tendría que dar también las gracias por conseguir casi un centenar de matriculados y propiciar ese ambiente mágico y cordial que vivimos durante aquellos tres calurosos días del julio almagreño.

Gracias a los ponentes, a los mexicanos y a los españoles, que nos han permitido acercarnos a la figura de Sor Juana Inés de la Cruz y al teatro novohispano. Tuvimos la suerte de contar con la presencia de Margo Glantz que, con su saber y simpatía, inauguró brillantemente esta edición, en un entusiasta y rico diálogo con Beatriz Aracil. Contamos también con Sara Poot Herrera, Carmen López Portillo, Judith Farré y Javier Rubiera que nos ilustraron sobre diversos aspectos de la obra de Sor Juana y del teatro novohispano. Un capítulo aparte mereció Juan Ruiz de Alarcón, el otro gran dramaturgo mexicano, a quien dedicaron sus intervenciones Germán Vega García-Luengos y José Montero.

Un apartado especial merece la aportación de los directores y actores que pasaron por nuestros coloquios para explicar su trabajo y atender todo tipo de cuestiones y sugerencias. La presencia de Helena Pimenta y los actores de la CNTC en el último coloquio puso el broche de oro a esta edición. A todos ellos, muchas gracias.

Todo ello fue posible gracias a un equipo entusiasta y experimentado formado por Elena Marcello, Almudena García, Alberto Gutiérrez, Conchi Astilleros y Roberto González, con la ayuda inestimable de nuestros becarios: José Luis Muñoz, Carmen Santana, Andrea Espadas y Celia Román.

Esperemos que estas actas reflejen de alguna manera lo mucho que disfrutamos y lo mucho que aprendimos en estas entrańables Jornadas dedicadas a Sor Juana.

Rafael González Cañal

Universidad de Castilla-La Mancha 


\title{
Sor Juana Inés de la Cruz y el teatro novohispano
}

\author{
XLII Jornadas de teatro clásico de Almagro
}

\author{
Almagro, 9, 10 y 11 de julio de 2019
}

DiRECCIÓN

Rafael González Cañal

SeCretaría

Almudena García González

COMISIÓN ORGANIZADORA

Elena E. Marcello,

Alberto Gutiérrez Gil

María Concepción Astilleros

BECARIOS

José Luis Muñoz Muela

Carmen Santana Bustamante

Andrea Espadas Ureña

Celia Román Álvarez 


\section{Programa}

\section{Martes 9}

10:30 Recepción y entrega de documentos

11:00 Inauguración de las Jornadas

11:30 Margo Glantz (Univ. Nacional Autónoma de México y Academia Mexicana de la Lengua): En las aguas de Narciso: la producción dramática de Sor Juana. Diálogo con Beatriz Aracil (Univ. de Alicante)

13:30 Libros en escena

Mar Zubieta:

Publicaciones de la Compañía Nacional de Teatro Clásico

13:30 Visita al corral de comedias

18:00 Germán Vega García-Luengos (Univ. de Valladolid): Lo que aún no sabiamos de Ruiz de Alarcón

19:00 José Montero Reguera (Univ. de Vigo): La complejidad estilistica de «La verdad sospechosa» de Ruiz de Alarcón

22:45 Representación teatral: Valor, agravio y mujer y El conde Partinuplés, de Ana Caro (Fundación Siglo de Oro/ Rakatá). Palacio de los Oviedo

\section{Miércoles 10}

10:00 Sara Poot Herrera (Univ. de California, Santa Bárbara \& UC-Mexicanistas):

Sor Juana y "una cómica», actriz que recitó el poema del «Neptuno Alegórico»

11:00 Judith Farré (Consejo Superior de Investigaciones Científicas):

"Los empeños de una casa", el diseño de un festejo teatral

12:30 Coloquio sobre la representación de Valor, agravio y mujer y El conde Partinuplés, de Ana Caro: Rodrigo Arribas y Fernando GIL

17:30 Álvaro CuÉlLAR (Universidad de Kentucky, EEUU): El teatro de Alarcón y Sor Juana de la Cruz ante las humanidades digitales

18:00 Presentación del número dedicado a Sor Juana Inés de la Cruz de la revista Inundación Castálida

Carmen López Portillo Romano 
19:00 Coloquio sobre la puesta en escena de Los empeños de una casa de Sor Juana Inés de la Cruz

Manuel Canseco (director escénico), Ignacio García (director escénico) y Yayo CÁceres (director escénico)

Presenta: Antonio Serrano

22:45 Representación teatral: El castigo sin venganza, de Lope de Vega (CNTC). Hospital de San Juan

\section{Jueves 11}

10:00 Carmen López Portillo Romano (Univ. del Claustro de Sor Juana, México):

De Fibonacci a Sor Juana

11:00 Javier Rubiera (Univ. de Montreal, Canadá): El teatro evangelizador novohispano en el contexto del teatro misionero del siglo $X V I$

12:30 Coloquio sobre la representación de El castigo sin venganza, de Lope de Vega (Compañía Nacional de Teatro Clásico). Intervienen: Helena Pimenta, Joaquín Notario, Beatriz Argüello y Rafa Castejón.

13:45 Clausura 



\section{EL TEATRO EVANGELIZADOR NOVOHISPANO EN EL CONTEXTO DEL TEATRO MISIONERO DEL SIGLO XVI, CON JAPÓN AL FONDO}

Javier Rubiera

Université DE MontréAL

Orcid: 0000-0002-0273-7116

http://doi.org/10.18239/cor_45.2021.07

El teatro es mucho más que los textos verbales que conforman una literatura dramática. Hay un tipo de Historia literaria que se ocupa fundamentalmente del estudio de los poetas dramáticos en su contexto cultural y del análisis y de la crítica de sus obras. Hay, por otra parte, una Historia del teatro que acoge a la anterior, pero que debe dar cuenta de otro tipo de prácticas escénicas no específicamente literarias. A veces sabemos de la existencia de esas prácticas únicamente por fuentes indirectas y por relaciones descriptivas de espectáculos, siempre en el ámbito de una celebración festiva de la que forman parte, de cuyo aspecto verbal, si lo hubo, no queda, sin embargo, testimonio. Esto lo saben particularmente bien los que se han dedicado o se dedican al estudio del teatro medieval castellano, y en general los estudiosos del teatro durante la Edad Media en Europa, pero también durante los siglos XVI y XVII. ¿¿A cuántos congresos, coloquios y simposia no habremos asistido en los que los debates se prolongaban, se enredaban y se encrespaban al discutir sobre lo que es teatro o no es teatro? En ese tipo de foros se multiplicaban, por ejemplo, las polémicas sobre cómo es posible de- 
limitar las esferas de la fiesta, del teatro, del juego, del rito y del espectáculo, sobre qué es, entonces, la teatralidad, o dónde puede encontrarse ${ }^{1}$, sobre si es útil la introducción del término "parateatralidad» o si es pertinente aquel otro de "performance» de P. Zumthor, tan apreciable en el ámbito de la oralidad medieval, de los juglares y trovadores.

El teatro puede tener un enorme impacto sobre una sociedad. Lo que llamamos Occidente sabe no solo del atractivo estético del teatro sino de su poder retórico, de su fuerza de convencimiento, gracias a su naturaleza imitativa, a la técnica audiovisual y a la participación del cuerpo en acción a la vista de una comunidad, sobre todo cuando en el espectáculo intervienen el canto y la danza.

Por otro lado, una perspectiva de gran interés para mí, como investigador, es la del teatro como forma viajera que sirve de vehículo cultural y produce formas nuevas que combinan o sintetizan elementos de tradiciones diversas. Me interesan los casos individuales de poetas, por poner dos ejemplos bien conocidos entre otros muchos, como P. Claudel que viaja a Japón y ve allí el Nō y el Kabuki, o de A. Artaud que recibe el espectáculo de las danzas balinesas con entusiasmo. ¿Qué impacto tiene sobre ellos y sobre su obra, cómo la hacen transformar y qué efectos provocan sobre la práctica escénica de su tiempo y de los siguientes? Pero me interesan otros fenómenos grupales, que se prolongan en el tiempo y que provocan encuentros o conflictos entre comunidades culturales. Me refiero a grupos de personas que se desplazan a otros espacios no con la intención primera de hacer teatro. No van a hacer teatro como iría una compañía, sino que deciden utilizarlo como un medio de influir decisivamente en la conducta de otros pueblos o comunidades, modificando sus costumbres. Hablo, entonces, del teatro como forma o manifestación que pone en contacto a gentes de diferentes culturas, a veces muy alejadas, y que sirve de vehículo de ideas y de costumbres. En este sentido, puede propiciar un diálogo cultural, pero tal uso del teatro puede ser o puede interpretarse también como instrumento de dominación ideológica, de imposición política y moral. Pienso que todas estas consideraciones previas son muy convenientes para introducir el tema del «teatro de evangelización» o «teatro misionero» que nos ocupará en las próximas páginas.

\section{EL TEATRO MISIONERO IBÉRICO}

Particularmente durante el siglo XVI, el teatro en la Península Ibérica aparte de un divertimento y de un espectáculo fue un poderoso instrumento de catequesis que

1 Sobre esta cuestión aplicada al caso de la Nueva España véanse las reflexiones de Hernán Ramírez [2009]. 
reforzó las creencias religiosas del pueblo con la dramatización de la Historia sagrada, tanto del Antiguo como del Nuevo Testamento. Se conservan decenas de piezas breves - llamadas, entre otras denominaciones, farsas, coloquios o autos- que escenifican, junto a vidas de santos, los episodios más conocidos de las Sagradas Escrituras, como aquellos que tienen por protagonistas a Adán y Eva en el paraíso, a Abraham y el sacrificio de su hijo Isaac, a Moisés o a Nabucodonosor, por recordar cuatro historias famosas de las que se conserva el texto dramático escrito entre las numerosas piezas de la colección de noventa y seis obras que compone el famoso tesoro del Códice de autos viejos. Durante los siglos XV y XVI, como es propio de toda el área románica, se representan piezas compuestas para extender y profundizar la propaganda de la fe popular, en las que se mezclan elementos sagrados y elementos profanos de contenido cómico, plegarias con chistes, en un espectáculo en el que la música y el canto tienen una presencia obligada para dotar de mayor atractivo a todo el conjunto escénico.

La intención didáctico-moralizadora de este tipo de teatro se puso especialmente de manifiesto durante las campañas de evangelización y de catequesis que los misioneros principalmente españoles y portugueses llevaron a cabo en territorio americano durante el siglo XVI. Hablamos, sobre todo, de franciscanos — desde 1523 en la Nueva España-, pero también de otras órdenes, como dominicos o agustinos, y más tarde jesuitas — desde 1549 en Brasil y desde 1572 en la Nueva España. Este teatro de evangelización trasladó a América, en distintas lenguas indoamericanas como el náuhatl o el tupí, historias bíblicas y hagiográficas similares a las representadas en Europa, adaptadas ahora para el nuevo receptor indígena, inserto en códigos ideológicos, lingüísticos y sociales bien diferentes. Muy representativo de esta situación es el teatro misionero en náhuatl que dramatizaba historias religiosas de la tradición judeocristiana a fin de evangelizar a los indígenas, mezclando, junto con el mensaje cristiano y la técnica occidental de representación, elementos retóricos del náhuatl y componentes abiertamente prehispánicos.

El teatro de evangelización en la Nueva España, promovido principalmente bajo la dirección de los frailes franciscanos, ha sido muy bien estudiado en los últimos cincuenta años y es casi rigurosamente paralelo a otro, mal conocido aún, llevado a cabo por jesuitas españoles y portugueses al otro lado del mundo, en el Extremo Oriente. En 1598, año de la muerte de Felipe II, se publicó en Évora una obra en dos tomos que reúnen la más extensa colección de cartas enviadas por los misioneros jesuitas desde China y Japón ${ }^{2}$. Leídas con atención, estas cartas — y otras de la misma

2 Cartas que os padres e irmáos da Companhia de Iesus escreverão dos Reynos de Iapão \& China aos da mesma Companhia da India \& Europa, desdo anno de 1549 ate o de 1580. 
naturaleza publicadas con anterioridad en Coimbra y en Alcalá- ofrecen gran número de datos que nos hablan del uso de la música, de cantos y de representaciones dramáticas como uno de los medios de evangelización en tierras japonesas. También en Japón se va a producir, entonces, el mismo uso del teatro como vehículo de la propaganda religiosa, adaptándose esta vez las historias sagradas cristianas para un receptor que opondrá una mayor resistencia a la evangelización. Esto es debido, entre otros factores, a que tal propaganda no va precedida o acompañada de una campaña de conquista militar ni de un proyecto general de colonización, y, por lo tanto, tiene lugar en un territorio no dominado por las coronas portuguesa y española, sino en un territorio insular de una extensión muchísimo más limitada que la americana y con una unidad lingüística y cultural muy diferente de la compleja situación de Mesoamérica, por ejemplo.

Desde hace años desarrollo un proyecto ${ }^{3}$ que trata sobre algunos aspectos del peculiar episodio de la presencia misionera ibérica en Japón durante el siglo XVI, a partir de 1549, fecha de la llegada de Francisco Javier a la costa japonesa, acompañado de otros dos jesuitas españoles, el padre Cosme de Torres, valenciano, y el hermano Juan Fernández, cordobés. Cosme de Torres será el Superior o director de la misión entre 1551 y 1570 , periodo durante el cual se produjo un conflictivo intercambio cultural en el que el teatro jugó un papel tan importante como sugerente. A través de la interpretación de diferentes documentos del siglo XVI — particularmente cartas enviadas desde la misión de los jesuitas en Japón- este proyecto trata de concretar el modo en el que los misioneros utilizaron las representaciones dramáticas para reforzar su campaña de evangelización, llegando a usar recursos escénicos propios de la tradición autóctona para adaptar el mensaje cristiano a la mentalidad japonesa. Con objeto de contextualizar e interpretar adecuadamente este rico encuentro teatral entre Oriente y Occidente, propiciado por los intentos de evangelización de españoles y portugueses, es mi opinión que debe ponerse en relación comparativa con el teatro catequístico desarrollado en la Península Ibérica y con el teatro de evangelización en tierras americanas.

\section{UNA NUEVA PERSPECTIVA}

Con el fin de abrir nuestra mirada, propongo en este trabajo una nueva perspectiva desde la que observar el teatro de evangelización en Nueva España: se trata

3 Le théâtre et la rencontre des cultures ibérique et japonaise au I 6 e siècle. Este proyecto está financiado por el «Conseil de recherche en sciences humaines» de Canadá (2016-2020). 
de una perspectiva comparativa, en el contexto del teatro misionero propiciado por la expansión de las coronas portuguesa y española en el siglo XVI. Hablamos de una expansión geográfica hacia América y hacia Asia que está relacionada con una expansión de la cristiandad y, en concreto, con la búsqueda de nuevas gentes a quienes convertir al catolicismo en un momento de fuerte crisis interna entre los cristianos europeos, tras el movimiento de la Reforma. Pero el contexto misionero del que hablo —expansión evangelizadora en relación con la expansión ibérica - nos obligará a salirnos de las relaciones transatlánticas para introducir la perspectiva transpacífica, resultado de la revolución magallánica producida por las consecuencias de la primera circunnavegación.

La expansión europea hacia Asia por la ruta de Oriente, doblando el Cabo de Buena Esperanza y dirigiéndose hacia el Océano Índico, se había llevado a cabo estableciendo la ruta portuguesa. Será la nueva ruta de las especias, que conducía a La India y a las Molucas, y ponía a Portugal en relación con la China. También en el contexto de esa empresa Portugal y los jesuitas ibéricos llevan allá el teatro: a La India (a Goa y Cochín) y a Japón. E incluso en los barcos, según estudió Mário Martins [1973], en el curso de largas travesías que se prolongaban durante muchos meses, se representaban autos: hay al menos testimonio de ello en ocho piezas, una de ellas en castellano, a partir de 1574, pero es muy posible, y lógico, que ya con anterioridad, para celebrar fiestas como el Corpus, se hicieran representaciones cuya preparación y cuyos ensayos ayudarían a pasar el largo tiempo de la travesía.

Nos situamos, por lo tanto, en un momento histórico entre 1520 y 1590 en el que se produce un teatro evangelizador en diversos territorios americanos y asiáticos organizado por misioneros principalmente ibéricos, portugueses y espańoles. El mejor conocido de los teatros misioneros es el desarrollado en la Nueva Espańa y por ello puede servir como piedra de toque y elemento de comparación privilegiado con el fin de establecer los parecidos y las diferencias entre las diversas manifestaciones teatrales misioneras en el mundo. Precisemos, en primer lugar, que dentro del teatro desarrollado en Nueva Espańa el franciscano es el que ha sido investigado más a fondo y puede considerase como el teatro de evangelización por antonomasia. Hay otros menores, poco estudiados y concretados en sus formas, debido a la falta de datos y de documentos que lo testimonien mejor, y a que sin duda tuvieron menos importancia, como el teatro dominico, el teatro agustino o el teatro jesuítico de época más tardía, distinto del teatro de colegio. En segundo lugar, hay que recordar la existencia de la utilización del teatro como medio de evangelización en otras áreas geográficas bajo el dominio de la Corona española: hoy se estudian más bien desde la perspectiva de la li- 
teratura de una determinada república o nación americana al hablar de su prototeatro y de las prácticas escénicas en tiempos de la Colonia. Así en las historias al uso se encontrarán breves apartados dedicados a los orígenes del teatro en Argentina, en Perú, en Bolivia, en Chile, en Colombia, en Paraguay... aunque no siempre se encontrarán datos sobre esas prácticas en el siglo XVI, porque en algunos casos son más tardías. En tercer lugar, hay otro teatro misionero de gran importancia en la América no española: el teatro en Brasil. Es desarrollado en territorios pertenecientes a la Corona portuguesa por medio de la orden jesuita que llega en 1549, en rigurosa simultaneidad con su arribada a Japón. En este contexto juega un papel especialmente relevante el padre José de Anchieta, jesuita de origen canario considerado el fundador del teatro brasileño, que escribe algunas de sus obras utilizando diferentes lenguas — portugués, castellano, latín y tupí-, fenómeno de gran interés intercultural, dramático y lingüístico.

Pienso que hay dos líneas preferentes en la investigación a desarrollar por mi parte en el siglo XVI: una deberá poner en relación el teatro de evangelización realizado por una misma orden religiosa en dos ámbitos geográficos y culturales bien diferentes: los jesuitas en Brasil y en Japón. Por otro lado, la otra línea se ocupa del teatro misionero franciscano en la Nueva España puesto en comparación con el teatro evangelizador jesuita en Japón, comenzado a presentar aquí, que habrá que contrastar con más experiencias misioneras de otras áreas para obtener una mejor visión de conjunto en el futuro.

\section{COSME DE TORRES Y LA MIRADA TRANSPACÍFICA ${ }^{4}$}

Más allá de las diferencias propias entre la orden franciscana y la orden jesuita que puedan indicarse, los elementos comunes observables entre las experiencias misioneras en Japón y en la Nueva Espańa podrían explicarse por todo aquello que comparten como misioneros cristianos, en su formación y en sus objetivos. Por otro lado, las diferencias específicas de los pueblos objeto de la evangelización en contextos histórico-culturales diversos explicarían posibles disimilitudes. Ahora bien, ¿es posible que de alguna manera hubiera podido existir un conocimiento previo por parte de algún jesuita de la misión en Japón del experimento exitoso del teatro de evangelización franciscana en América y de algunos de sus métodos? No es imprescindible que así fuera para que brotara en tierras japonesas la idea del teatro como medio o instrumento de evangelización. Lo que se deduce de las Cartas analizadas — aunque hay

4 Sobre la cuestión transpacífica véanse estudios como los de Knauth [1972], Rivera Lake [2005] o Curvelo [2007]. 
que señalar que se perdieron muchas de personas y de épocas clave- es una evolución que rápidamente se explicaría así: a) consciencia de la importancia en el cuidado del aparato exterior en la ceremonia como modo de atracción de los nuevos fieles ${ }^{5}$; b) traducción de pasajes bíblicos que son leídos por un japonés; c) introducción de coloquios y cantos entre dos partes del coro durante la liturgia, combinando el japonés y el latín; d) representación de varios autos en la principales fiestas, particularmente durante el día de Navidad y del Domingo de Resurrección.

Sin embargo, hay un dato innegable al que no se ha prestado la debida atención, precisamente por no entender este hecho local, la evangelización del Japón, desde la perspectiva global de los teatros misioneros ibéricos. El Superior de la misión en Japón entre 1551 y 1570 fue el valenciano Cosme de Torres, quien a partir de las orientaciones de Francisco Javier imprime una huella muy significativa en la política de adaptación a las costumbres japonesas, adelantándose en varias décadas a la actitud de "accomodatio» — a la que luego nos referiremos - desarrollada en Asia por otros ilustres misioneros italianos de mayor fama, como Alessandro Valignano y Matteo Ricci. Cosme de Torres se hizo jesuita en Goa, donde completó sus ejercicios espirituales, movido por la fuerza y el carisma de Francisco Javier, a quien había conocido poco antes en Amboino (Islas Molucas) donde el misionero navarro iniciaba su labor de evangelización en el sureste asiático. Cosme de Torres era ya sacerdote entonces, aunque sin pertenecer a ninguna orden. ¿Qué hacía Torres en las Molucas, en ese momento territorio perteneciente ya a la Corona portuguesa? Pues había llegado allí como capellán de uno de los barcos de la expedición de Ruy López de Villalobos que había partido de la Nueva Espańa en 1542, «para [...] descubrir por la vía del poniente a la China o Malucos o cualquier islas de la Especiería» (409), como dice Bernal Díaz del Castillo en su Historia verdadera de la conquista de la Nueva España, y tratar luego de encontrar el viaje de vuelta a la Nueva Espańa, el tornaviaje, fundamental para establecer una comunicación eficaz entre Asia y América directamente. Lo que nos interesa señalar ahora es que Cosme de Torres, como recuerda en dos de sus primeras cartas [en Ruiz-de-Medina, 1990], había llegado a la Nueva España en 1538 - inducido por un fraile franciscano que murió al poco de llegar a América-y

5 Escribe Melchor Núñez Barreto a Ignacio de Loyola (Malaca, 3 de diciembre de 1554): «Dionos el señor visorei unas armas mui ricas para el rey de Bungo con otros dones de mucho precio. Inbíalas por un embaxador que connosquo va. Y hanos dado también un pontifical de tela de oro con sus [bordados], para allá con mucha solenidad celebrarmos los divinos oficios (porque la jente del Japón es mui polida y de mucho primor) y aun para más se movieren por estos exteriores al conocimiento de las [cosas] interiores y espirituales» [en Ruiz-de-Medina, 1990: 449]. 
estuvo allí al servicio del virrey don Antonio de Mendoza hasta su salida en la expedición de Villalobos en 1542. Es decir, se encuentra allí, y se refiere a su relación con los franciscanos que quieren que entre en su orden, durante el momento cumbre del uso del teatro de evangelización. Es verosímil pensar que Cosme de Torres habría tenido conocimiento por entonces de alguna representación concreta o tuviera noticia en general de los métodos franciscanos. Presento como hipótesis que este misionero español, que había vivido en México entre 1539 y 1542, adquirió, gracias a su condición de capellán del Virrey, conocimientos del teatro evangelizador franciscano en un momento clave de su desarrollo, lo que permitiría relacionar de modo concreto el papel del teatro misionero en la Nueva España con el papel del teatro misionero en Japón.

¿TRANSCULTURACIÓN, SIMBIOSIS, SÍNTESIS, IMPOSICIÓN IDEOLÓGICA?

Como señala Beatriz Aracil Varón al estudiar de modo ejemplar el caso de la Nueva Espańa, el teatro se presenta como uno de los «métodos especiales de conversión e instrucción religiosa», en un plano similar a la música y la danza, el canto, la pintura, el catecismo pictográfico o la pintura mural [1999: 8]. Tras haber probado anteriormente otros métodos o utilizándolos al mismo tiempo, se observa, entonces, que el teatro surge como uno de los medios más efectivos para atraer al otro y hacerle cambiar de ideas religiosas y de costumbres — conductas o comportamientos, si se prefiere-, es decir, convertirlo. Al tratar de caracterizar este tipo de teatro se suele recurrir a un modo de explicación que presenta, en primer lugar, la tradición del teatro religioso en la Península ibérica — en la que se inscribiría la práctica conocida por los franciscanos- $-y$, por otro lado, la controvertida teatralidad prehispánica, que tiene en cuenta la variedad de espectáculos integrados en diferentes celebraciones festivas indígenas. A partir de ahí se comienza a hablar, por ejemplo, de una «síntesis», de una «asimilación» o de una «fusión cultural».

Este estudio sobre los antecedentes, espańoles e indígenas, del teatro evangelizador quedaría incompleto sin una necesaria reflexión sobre la forma en que estas dos tradiciones espectaculares fueron asimiladas en las representaciones dramáticas misioneras. A este respecto, cabe recordar que el teatro evangelizador, concebido por los misioneros como un medio de imposición cultural sobre la población indígena, se convirtió a su vez en el punto de confluencia entre dos culturas, y que ha sido precisamente esta fusión cultural uno de los aspectos más destacados por los investigadores que han analizado este teatro. [Aracil Varón, 1999: 176] 
Este fenómeno de transculturación puede entenderse en sentido lato como un proceso de intercambio y de adaptación cultural -con sus transferencias, adopciones y resistencias-, pero se ha interpretado también desde una perspectiva muy frecuente en la crítica contemporánea que insiste en el componente ideológico negativo propio de esta confrontación conflictiva de culturas. Bien representativo de tal postura sería este pasaje en un difundido texto de Historia de la literatura hispanoamericana:

En definitiva, no sabemos si es válido asignar a este teatro un carácter ««mestizo». Se trata sin duda de dos culturas en contacto, pero no en pie de igualdad ni mucho menos. Lo cierto es que una de esas culturas usa de la otra para imponérsele. Pensamos que esto es lo verdaderamente esencial al ocuparnos del contenido y las formas del teatro misionero: el cómo uno y otras dependen de una función ideológica clara y la que [sic] tiene que ver con el sometimiento de los indios. El mestizaje, si es que así se le puede llamar, es artificial. No hay aquí una cultura "intermedia». Hay sólo dos culturas y una de ellas avasalla, "desde adentro», a la otra. [Shelly y Rojo, 1982: 323]

En este sentido, se observa como algo muy propio del estudio del fenómeno del encuentro, confrontación o conflicto entre culturas a través del teatro la reflexión en torno a la verdadera naturaleza y a la posibilidad misma de un intercambio cultural más o menos asimétrico, tal como se desprende, por ejemplo, de la lectura de varios textos incluidos en el volumen antológico El teatro franciscano en Nueva España. Fuentes y ensayos para el estudio del teatro de evangelización en el siglo XVI, coordinado por María Sten ${ }^{6}$.

Los intentos de pensar el proceso intercultural y sus resultados se mueven siempre alrededor de la difícil tarea de definir o determinar el «entre» y el modo en que se pasa o traspasa de un mundo a otro. Mestizaje, hibridismo e hibridación, sincretismo, transplante cultural, transculturación, simbiosis, aculturación inducida (M. León-Portilla), exfoliación (Robert Potter), reconciliación disfrazada (Max Harris), traducción cultural (Verónica Murillo), pasaje intercultural (Joachim Michael), son algunas de las categorías desde las que se intenta dar razón del proceso. Bien representativo del modo dual al que parece obligar la reflexión sobre el encuentro cultural a través del teatro y del desafío que supone su conceptualización sería el título del cono-

6 Recopilación de treinta ensayos clásicos y modernos (a veces fragmentos de obras mayores) sobre la cuestión enunciada en el título. Cuenta con dos Apéndices de Beatriz Aracil Varón con relaciones de piezas teatrales conservadas y de representaciones teatrales organizadas por misioneros. También de la propia Aracil Varón es un comentario bibliográfico muy adecuado. 
cido artículo de Armando Partida Tayzan, e incluido en la antología editada por Sten, planteado inteligentemente a modo de pregunta: «El sacrificio de Isaac: ¿colonización o integración escénica de dos culturas?».

Es muy frecuente encontrar en obras académicas recientes enfoques que identifican varios términos para tratar de dar cuenta de la complejidad y del dinamismo de los procesos estudiados, evitando aferrarse a una categoría única y estricta que los defina. A modo de ejemplo, pienso en series del tipo «encuentros, negociaciones e interacciones» o «transferencias, contaminaciones e innovaciones». Es un modo de tratar de resolver el problema eludiendo el uso de un término único, que no se considera adecuado para dar cuenta de procesos complejos. Porque verdaderamente de eso se trata, de procesos en los que intervienen numerosos agentes en situaciones cambiantes con resultados diversos. De ahí quizás la inconveniencia de ponerle un nombre a partir de categorías — gastadas rápidamente en el devenir de la crítica — utilizadas por disciplinas diferentes y desde presupuestos teóricos también diversos, lo que a veces solo contribuye a crear pasmo o perplejidad en los lectores. ${ }^{7}$ En los casos de teatro de evangelización que se pueden estudiar con cierto detalle a partir de documentos de la época, nos encontramos ante procesos de interacción entre dos grupos humanos de culturas alejadas, durante los que ocurre una transformación que da lugar a un nuevo producto o resultado, en nuestro caso en forma de representaciones dramáticas.

Tras esta reflexión de carácter terminológico y metodológico, pasemos ya a resumir algunas observaciones relativas al teatro misionero en Japón, tomando como orientación y piedra de toque comparativa el teatro de evangelización en Nueva Espańa, lo que nos permite repasar algunas de las características de ambas modalidades. Como parte de un estudio más amplio, adelantamos ahora las consideraciones generales sobre tres puntos: número de sacerdotes, número y variedad de obras representadas, y el modo o método de «acomodación» a los otros a través del teatro.

\section{Número de SACERdotes en la NueVa España y en Japón}

En primer lugar, conviene comenzar por hacer un comentario sobre el número de misioneros en las primeras décadas de la evangelización en uno y otro caso, en torno al momento del auge de este tipo de teatro. Fray Toribio de Benavente, en un pasaje en el que hace sus cálculos sobre la cantidad de naturales bautizados — por lo que

7 Sobre esta perplejidad, sobre el desgaste de las categorías y sobre la dificultad de pensar «mezclas y mestizajes» ya reflexionaba S. Gruzinski en unos pasajes fundamentales de su obra $E l$ pensamiento mestizo [2000: 39-63]. 
necesita introducir el número de sacerdotes—, afirma: «Hay a el presente [en 1536] en esta Nueva España obra de sesenta sacerdotes franciscanos, [...]. Demás de los sesenta sacerdotes que digo, se habrán vuelto a España más de otros veinte [...] y más de otros veinte que son ya difuntos" [1985: 158]. Los números son muy elocuentes de la gran movilización de los frailes en los trece primeros años de la presencia franciscana en la Nueva Espańa. Habla, por lo tanto, de unos cien sacerdotes, al margen de los de las otras órdenes (agustina y dominica) así como de los sacerdotes seglares. Si comparamos los datos con los de los trece primeros ańos de la presencia jesuita en Japón, notaremos lo que Ruiz-de-Medina ha llamado «escuálida cuadrilla de operarios» [1995: 41] con la que contaron: entre 1549 y 1562 solo se pueden contabilizar dieciséis misioneros, de los cuales cuatro estuvieron de paso, porque fallecieron o se regresaron el mismo año de su llegada. Solo cinco de ellos eran sacerdotes, algunos de efímera presencia. El resto fueron hermanos de la Compañía que llegaron como tales a Japón, o que fueron admitidos como hermanos allí, como los casos de los comerciantes portugueses Luis de Almeida — doctor en medicina—y Aires Sanches — con formación musical—, los casos de dos japoneses convertidos, llamados Lorenzo ${ }^{8}$ y Paulo, o el caso del huérfano portugués Guillermo Pereira'. Todos estos ejemplos son una prueba de la diferencia de horizontes de procedencia de los jesuitas en Japón: no todos eran graduados por la Sorbonne, como Francisco Javier, ni tuvieron una formación académica apurada, y muy pocos eran sacerdotes. El funcionamiento de la misión se ve reforzada, además, por la colaboración entusiasta de los auxiliares laicos japoneses: hombres, mujeres y niños de diferentes condiciones sociales, de los que han quedado numerosos testimonios y datos concretos.

${ }^{8} \mathrm{Al}$ convertirse al cristianismo el juglar semiciego Lorenzo Ryōsai (que años más tarde sería admitido como hermano en la Compańía), muy pronto se dieron cuenta los misioneros del efecto de aprovechar sus habilidades como narrador, acompañándose de un instrumento de cuerda pulsada llamado biwa, para contar ahora episodios de la historia sagrada cristiana. Creo que ese sería un paso que les animaría a probar otras técnicas de introducción de elementos de la tradición espectacular japonesa en el marco festivo religioso, llevando a cabo otros ejercicios de adaptación, quizás animados por los propios cristianos japoneses que verían el poder de atracción sobre los fieles, pero también sobre los gentiles, atentos a las actividades de aquellos extraños monjes venidos del Sur.

9 «Llevamos connosquo simco mochachos de los huérphanos que an venido de Portogal, los más aptos para deprender la léngoa y los más ensenhados en el canto llano y canto de órgano, para [en] las fiestas principales en que se representan las cosas de nuestra fee, los oficios divinos hazermos con gran solenidad. Porque la jente, con estos exteriores, se mueve en gran manera» [en Ruiz-de-Medina, 1990: 471]. 
Se aprecia que la misión jesuita en Japón va construyéndose con gran plasticidad a partir de pocos, pero muy variados elementos humanos, en una continua y hábil adaptación a circunstancias nada favorables: periodo de guerras internas entre daimios o señores feudales con frecuentes cambios de poder, animadversión de los bonzos budistas más poderosos, escasez de misioneros. Las aportaciones son muy variadas y el progreso de la misión — y del uso de la ceremonia y del teatro— va haciéndose según las habilidades y cualidades de los agentes humanos que se van incorporando. De muy especial importancia es esta variedad de «passeurs» o mediadores culturales de diferente condición (como L. de Almeida, Aires Sanches, Lorenzo Ryōsai o los niños huérfanos de origen portugués) y a ellos habrán de dedicarse futuras investigaciones que profundicen en las ya llevadas a cabo por Ruiz-de-Medina [1994 y 2003].

\section{NÚMERO Y VARIEDAD DE OBRAS REPRESENTADAS}

De la relación cronológica de representaciones teatrales organizadas por misioneros en la Nueva España, según la propuesta de B. Aracil Varón, se deduce que se pueden testimoniar entre 1533 y 1539 siete momentos festivos durante los que se representaron no más de quince piezas de las que conocemos el título. Por otra parte, en lo que Aracil Varón llama prudentemente "Relación alfabética de piezas teatrales conservadas que pueden vincularse a la actividad misionera del siglo XVI» aparecen once títulos de piezas escritas en náhuatl. ${ }^{10}$

Se deduce de las cartas enviadas por los misioneros que en territorio japonés se produjo muy pronto una notable utilización de las representaciones escénicas como medio de adoctrinamiento. Este es el listado de obras representadas con título o tema conocido, entre Navidad de 1560 y Navidad de 1566. Indicamos año, lugar y ocasión festiva de las representaciones ${ }^{11}$.

1560, Navidad:

Bungo
-La tentación de Adán (Adán y Eva en el Paraíso) -Juicio de Salomón -Adoración de los pastores

10 Digo "prudentemente», porque en la mayoría de los casos parece tratarse de reelaboraciones posteriores, en los siglos XVII y XVIII.

11 Para elaborar esta lista nos hemos orientado en los datos de Leims [1990], corroborados con nuestra propia lectura de diferentes volúmenes de cartas. El análisis de esta lista y de su significación, en relación con las obras representadas en Nueva España, es imposible en los márgenes de este trabajo ahora. 
1561, Navidad:

Bungo

1562, Pascua:

Bungo

1563, Navidad:

Ikitsuki

1563, Epifanía:

Ikitsuki

1563, Navidad:

Bungo

1564, Navidad:

Hirado

1565, Navidad:

Bungo

1566, Pascua:

Shimabara

1566, Navidad:

Bungo
-Arca de Noé

-Lot

-Triunfo de Abraham

-Adoración de los pastores

-Éxodo de Egipto de los hijos de Israel

-Episodio de Jonás y la ballena

-Adán y Eva en el Paraíso

-Anunciación del ángel y adoración de los pastores

-La Sibila y el Juicio Final

-Los Reyes Magos (Virgen María; Herodes)

-La tentación de Adán (Adán y Eva en el Paraíso)

-[Varias historias desde Adán hasta Abraham]

-Adoración de los pastores

-[Varias historias santas, incluyendo llegada de los padres de Roma]

-Adán y Eva

-Arca de Noé

-Visitatio Sepulchri

-El pecado de Adán

-Sacrificio de Abraham

-Lot

-El diluvio y el Arca

-José y sus hermanos

-Entrada de los israelitas en Egipto. 


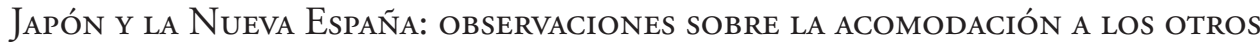
EN RELACIÓN CON EL TEATRO

Al observar que el teatro de evangelización fue promovido principalmente por la orden franciscana en la Nueva España y por la orden jesuita en Japón, podría pensarse en una diferencia en el modo o método de aculturación, porque de una manera simplificada suele decirse que los jesuitas desarrollaron en Asia un método de «accomodatio», de acomodación a los usos y costumbres de los pueblos a evangelizar, mientras que las órdenes mendicantes eran partidarias de un método de "tabula rasa".

Sin embargo, en lo que se refiere a los cantos, a las danzas y al teatro parece que en los periodos que estudiamos siguieron un método muy parecido. Como hemos dicho ya, contamos para el caso del uso del teatro en la evangelización en Japón con noticias y con datos de mucho interés a partir de las cartas de los misioneros. De esta cartas a modo de informes y relaciones de lo acontecido en la misión, no es difícil extraer citas que permiten ya hacerse una buena idea del ejercicio de adaptación que los jesuitas, con gran flexibilidad, llevaron a cabo, pues se indica explícitamente la utilización del japonés en las composiciones, tal como demuestran repetidas expresiones del tipo: «Ao modo do Iapão», «a sua maneira», «sus motetes en japam», «a qual [historia] esta traduzida em lingoa do Japão», «na mesma lingoa do Japão», «tudo tirado na lingoa da terra».

En algunos casos se trata únicamente de noticias de cierta brevedad, aunque llenas de interés en su concisión, como estos dos testimonios:

La fiesta de Navidad se celebra aquí también con mucha alegría. [Para ella] los cristianos japoneses vienen todos con sus autos, que preparan desde muchos días antes, en los que representan muchas historias de la Sagrada Escritura, de mucha doctrina. Sobre estas historias se componen cantos y trovas a su manera, que cantan de continuo ${ }^{12}$.

Para este día tenía hecha Paulo en la lengua de Japón, en un cierto modo de verso que acostumbran a cantar los japoneses, toda la historia del Sepulcro de Cristo y de la respuesta del Ángel a las Marías, etc ${ }^{13}$.

En otros casos nos encontramos ante descripciones más elaboradas y precisas - que ya he recogido y comentado en otros artículos- como las de la carta de Juan Fernández de 8 de octubre de 1561 o algunas de excepcional interés como la de Aires

12 Original en portugués. Carta de Luis de Almeida a Antonio de Quadros (Funai, 1 de octubre de 1561).

13 Original en portugués. Carta de Belchior de Figueiredo (13 de septiembre de 1566). 
Sanches del 11 de octubre de 1562 y la de Belchior de Figueiredo, de 27 de noviembre de 1567 [Rubiera, 2012 y 2019]. Sin embargo, no contamos con ningún texto que iguale los magníficos relatos incluidos por Fray Toribio de Benavente (Motolinía) en su Historia de los indios de Nueva España — donde se encuentran esos documentos extraordinarios con las descripciones de las Fiestas de Corpus Christi y otras fiestas en Tlaxcala, en 1538 y 1539-, momento cumbre del teatro de evangelización.

En todo caso, son numerosos los textos extraidos de las cartas del Japón que pueden hermanarse sin problema con algunos del recién aludido Motolinía en la Nueva España, como este:

Celebran las fiestas y pascuas del Señor y de Nuestra Señora y de las advocaciones principales de sus pueblos con mucho regocijo y solemnidad, Adornan sus iglesias muy pulidamente con los paramentos que pueden haber, [...] y por donde tiene de pasar la procesión hacen muchos arcos triunfales. [...] Los indios señores y principales, ataviados y vestidos de sus camisas blancas y mantas labradas con plumajes y con piñas de rosas en las manos, bailan y dicen cantares en su lengua de las historias que celebran, que los frailes se los han traducido y los maestros de sus cantares las han puesto a su modo de manera de metro que son graciosos y bien entonados. [1985: 118]

De modo general, el proceso de adaptación es fenómeno que ha estudiado con experta atención el antropólogo Carmelo Lisón Tolosana en su libro La fascinación de la diferencia. La adaptación de los jesuitas al Japón de los samuráis. A partir de las biografías de tres figuras claves de la intervención jesuítica en Japón, (Francisco Javier, Cosme de Torres y Alessandro Valignano) desde una perspectiva entre histórica y antropológica, explica muy bien el proyecto de deseuropeizar la evangelización de Japón y el proceso de acomodarse a la naturaleza y las costumbres de los japoneses, no sin obstáculos dentro de la propia Iglesia y de la misma Compañía, donde no todos están de acuerdo con el método. Es en este contexto, evidentemente, en el que hay que enmarcar el teatro misionero, el uso de la lengua japonesa en cantos y ritos, y la adopción de técnicas de representación autóctonas.

No cabe duda de que los misioneros jesuitas realizan un extraordinario esfuerzo de acomodación a la cultura japonesa, pero es cuestionable utilizar la actitud más representativa del espíritu evangelizador jesuita ${ }^{14}$ (el método de "accomodatio») para oponerlo sistemáticamente al método de las órdenes mendicantes (franciscanos, do-

14 Como ya hemos comentado, es la actitud defendida por Alessandro Valignano que poco más tarde tendrá una influencia muy importante sobre la labor de Matteo Ricci en China, aunque esta actitud se encuentra ya de lleno inscrita en el método de Cosme de Torres desde décadas antes. 
minicos y agustinos), reducido de modo abusivo como método de «tabula rasa». El problema es la generalización absoluta, la simplificación y la reducción. Si bien es cierto que esa parece haber sido su actitud en Asia en el último tercio del XVII —induciéndoles a criticar furiosamente el método jesuítico que les llevaba a vestir, comer y comportarse como japoneses-, basta el ejemplo del teatro misionero franciscano en América para desmentirlo, tal como han señalado algunos críticos en los últimos años. Por ejemplo, Beatriz Aracil Varón, al tratar la debatida cuestión del componente indígena en el teatro misionero novohispano, admite la presencia de un «referente cultural prehispánico» que:

tuvo siempre como función primordial servir a los objetivos de la evangelización y que por ello, comprendió solo aquellos aspectos que los misioneros consideraron válidos para este fin, lo cual, por otro lado, no implicaba necesariamente una recepción unívoca por parte del público indígena, que pudo interpretarlos en algunos casos de acuerdo a anteriores creencias [1999: 180]..$^{15}$

De modo general, puede decirse que, en ambos casos, Japón y la Nueva España, se observa que los misioneros permitieron y alentaron la utilización de la lengua propia de los nuevos cristianos, y el uso de sus cantos y danzas durante las fiestas, particularmente durante las representaciones. En los espectáculos había partes habladas y cantadas en la lengua autóctona (náhuatl o japonés), que traducían los textos sagrados, y partes cantadas en latín. En el caso japonés hay que señalar una notable peculiaridad de gran interés para la Historia del teatro: el hecho, sin paralelo en el modelo de la Nueva España, de que se contaba en Japón con una tradición escénica estrictamente codificada que se utilizaba para contar y mostrar las historias relacionadas con el mundo budista y sintoísta. Me refiero a lo que de modo moderno llamamos teatro Nō, algunas de cuyas técnicas fueron aprovechadas en ocasiones por los misioneros para adaptar la historia sagrada cristiana a la mentalidad japonesa ${ }^{16}$.

15 Aracil Varón parece aludir aquí a lo que James Lockart llamó «double mistaken identity». Sobre la cuestión véase el trabajo de Solange Alberro [1990].

16 Me he referido específicamente a este tema en mis dos artículos [2012 y 2019], de los que me he valido para la elaboración de algún párrafo de este texto. Sobre el teatro de los jesuitas en Japón es fundamental tener en cuenta los libros de Bourdon [1993] y de Leims [1990], así como los estudios recientes de Isgrò [2016] y Takao [2017]. 
EL TEATRO EVANGELIZADOR NOVOHISPANO EN EL CONTEXTO DEL TEATRO MISIONERO DEL SIGLO XVI

\section{BibLIOGRAFÍA}

Alberro, Solange [2000]: «Los franciscanos y la tabula rasa en la Nueva España del siglo XVI: un cuestionamiento", en El teatro franciscano en la Nueva España. Fuentes y ensayos para el estudio del teatro de evangelización en el siglo XVI, ed. M. Sten, México, unam-Conaculta-Fonca, pp. 21-38.

Aracil Varón, María Beatriz [1999]: El teatro evangelizador: sociedad, cultura e ideología en la Nueva España del siglo XVI, Roma, Bulzoni.

Benavente, Fray Toribio de [1985]: Historia de los indios de la Nueva España, ed. Claudio Esteva, Madrid, Historia 16.

- [1996]: Memoriales (Libro de oro, Ms Jgi 31), ed. N. J. Dyer, México D. F., El Colegio de México.

Bourdon, Leon [1993]. La Compagnie de Jésus et le Japon (1547-1570), Paris-Lisbonne, Fondation Calouste Gulbenkian-Comission Nationale pour les Commémorations des découvertes portugaises.

Cartas que os padres e irmãos da Companhia de Iesus escreverão dos Reynos de Iapão \& China aos da mesma Companhia da India \& Europa, desdo anno de 1549 ate o de 1580, [1598], Évora, Manuel de Lyra.

Curvelo, Alexandra [2007]: Nouvens douradas e paisagens habitadas. A Arte Namban e a sua circulação entre a Asia e a America: Japão, China e Nova Espanha (c. 1550-c. 1700), Universidade Nova de Lisboa. [Tesis Doctoral].

Díaz del Castillo, Bernal [1984]: Historia verdadera de la conquista de la Nueva España, ed. M. León-Portilla, Madrid, Historia 16.

Gruzinski, Serge [2000]: El pensamiento mestizo, Barcelona, Paidós.

Hernán Ramírez, Hugo [2009]: Fiesta, espectáculo y teatralidad en el México de los conquistadores, Frankfurt-Madrid, Vervuert-Iberoamericana; México, Bonilla-Artigas.

IsGrò, Giovanni [2016]: L'aventura scenica dei gesuiti in Giappone. 1549-1639, Bari, Edizioni di Pagina.

KNAUth, Lothar [1972]: Confrontación transpacifica: el Japón y el nuevo mundo hispánico, 1542-1639, México, unAM-Instituto de Investigaciones Históricas.

LeIms, Th. [1990]: Die Entstehung des Kabuki: Transkulturation Europa-Japan in 16. und 17. Jahrhundert, Leiden/New York, E. J. Brill.

Lisón Tolosana, Carmelo [2005]: La fascinación de la diferencia. La adaptación de los jesuitas al Japón de los samuráis, 1549-1592, Madrid, Akal.

Martins, Mário [1973]: Teatro Quinhentista nas Naus da India, Lisboa, Brotéria. 
Partida Tayzan, Armando. 2000. [2000]: «El sacrificio de Isaac: ¿̨colonización o integración escénica de dos culturas», en El teatro franciscano en la Nueva España. Fuentes y ensayos para el estudio del teatro de evangelización en el siglo XVI, ed. M. Sten, México, unam-Conaculta-FonCa, pp. 265-280.

Rivera Lake, Rodrigo [2005]: El arte Namban en el México virreinal, Madrid, Turner.

RUBiERA, Javier [2012]: «Un episodio de transculturación: para un estudio del teatro misionero ibérico en Japón", en Japón y España: acercamientos y desencuentros (siglos XVI y XVII), ed. M. J. Zamora Calvo, Gijón, Satori, pp. 197-211.

— [2019]: "Western Sacred Plays and Nō Style», en Faraway Settings: Spanish and Chinese Theaters of the 16th and 17th Century, ed. J.P. Gil-Osle y F. A. de Armas, Madrid-Frankfurt am Main, Iberoamericana-Vervuert, pp. 209-224.

Ruiz-De-Medina, J. ed., [1990]: Documentos del Japón 1547-1557, Roma, Instituto Histórico de la Compañía de Jesús.

— [1994]: "The Role of Children in the Early Japanese Church», en Portuguese Voyages to Asia and Japan in the Renaissance Period, Peter Milward, ed., Tokyo, The Renaissance Institute, pp. 59-78.

- ed., [1995]: Documentos del Japón 1558-1562, Roma, Instituto Histórico de la Compañía de Jesús.

- [2003]: "The Role of the Blind Biwa Hōshi Troubadours in the History of the Christian Mission in Japan ", Bulletin of the Portuguese-Japanese Studies, 6, pp. 107-145.

Shelly, K. y G. Rojo [1982]: «El teatro hispanoamericano colonial», en Historia de la Literatura Hispanoamericana. Tomo I. Época colonial, ed. L. Íñigo Madrigal, Madrid, Cátedra, pp. 319-352.

STEn, María, ed., [2000]: El teatro franciscano en Nueva España. Fuentes y ensayos para el estudio del teatro de evangelización en el siglo XVI, comp. Ó. A. García y A. Ortiz Bullé-Goyri, México, unam-Conaculta-FonCa.

TAKaO, Makoto Harris [2017]: Encounters in the Glocal Mirror. The Role of the Performing Arts in Japan's Christian Century and its Reflection in Early Modern Europe, 1543-1783, University of Western Australia. [Tesis Doctoral]. 